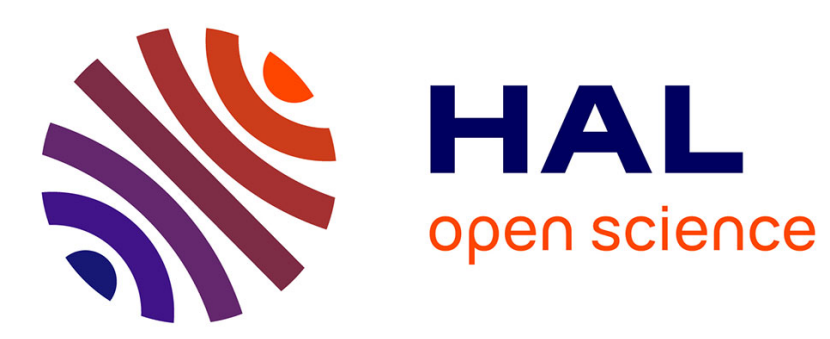

\title{
Putting to Test a Model of Self-Evaluation of The Learning Method in an e-Learning Environment
}

\author{
Jonathan Kaplan
}

\section{To cite this version:}

Jonathan Kaplan. Putting to Test a Model of Self-Evaluation of The Learning Method in an eLearning Environment. International Conference on Technology and Innovation in Learning, Teaching and Education (TECH-EDU 2018), Jun 2018, Thessaloniki, Greece. halshs-01941582

\section{HAL Id: halshs-01941582 \\ https://shs.hal.science/halshs-01941582}

Submitted on 1 Dec 2018

HAL is a multi-disciplinary open access archive for the deposit and dissemination of scientific research documents, whether they are published or not. The documents may come from teaching and research institutions in France or abroad, or from public or private research centers.
L'archive ouverte pluridisciplinaire HAL, est destinée au dépôt et à la diffusion de documents scientifiques de niveau recherche, publiés ou non, émanant des établissements d'enseignement et de recherche français ou étrangers, des laboratoires publics ou privés. 


\title{
Putting to Test a Model of Self-Evaluation of The Learning Method in an e-Learning Environment
}

\author{
$1^{\text {st }}$ Jonathan Kaplan \\ Institut des Sciences et Pratiques d'Éducation et de Formation \\ Éducation, Cultures \& Politiques research unit (EA 4571) \\ Université Lumière Lyon 2 \\ Lyon, France \\ CHArt - Université Paris Nanterre (EA 4004) research unit \\ jonathan.kaplan@univ-lyon2.fr
}

\begin{abstract}
This paper describes the process and results of a study that put to test a model of self-evaluation of the learning processes which had emerged from a previous study. As in the previous study, this study examined self- and co-regulation strategies, in particular learners' assessment strategies that learners perceived to have used during a university course within an e-learning environment. In the previous study [1], collective evaluation of the targeted learning content - a co-regulation strategy-, and to a lesser extent, individual environmental control, both predicted individual self-evaluation of the study method. Using the same research method, the study presented in this paper aimed at examining learners' self-evaluation of their study method to test if a similar explicative model emerged. Furthermore, the present research studied two student groups, learning within the same course but with separate instructors. Studying two groups enabled to compare perceived regulation of learning strategies used. Subjects were postgraduate students in Educational Sciences studying on a digital campus in a French university during the academic year 2017-18. Data was collected using the ERICA scale [2]. The study found that the same explicative model applied, though the explicative power of the model was weaker. It also revealed that the two groups of learners did not differ significantly. These findings are discussed followed by suggestions for the design of e-learning environments.

Index Terms - self-regulation, co-regulation, learning strategies, assessment, self-evaluation
\end{abstract}

\section{Context}

Almost 30 years have passed since researches took to studying ways learners manage their learning under the banner of Self-Regulated Learning (SRL). Initially, interest was focused on strategies used by students in primary and secondary education. Zimmerman \& Martinez-Pons [3] found that students who were better self-regulators and had used more regulation strategies were those who achieved better academic results. Researchers have since distinguished between motivational, cognitive and affective dimensions related to regulating learning. One strand of research in the field has referred more readily to metacognitive strategies learners use [4]. Recently, the study of strategies for learning has shifted to include regulation that involves other learners in a reciprocal manner. A shift of focus from the individual learner to the group has also attracted interest [5]-[11].

The research presented in this paper was conducted as part of a research program inquiring into the relationship between environmental conditions and strategies to regulate learning. The relationship between the environment and regulation of learning has not attracted much attention. The relationship between the environment and SRL strategies needs more attention for several reasons. The first reason pertains to the socialcognitive [12], [13] backdrop of research in the field in which the environment is a constituent part. The human environment has received some attention, though tittle attention has been directed toward the material environment. Material environments are constantly evolving. This is particularly true of digital environments which are now ubiquitous in education. The interplay between the environment and the learning process should not be neglected as environments can be enabling to different degrees in terms of their ability to provide support for different types of learning strategies. Some strategies may be preferred by some individuals while others may be more effective for successful learning. The second reason to study the relationship between environments and learning processes is that knowledge needs to be generated about cognitive ergonomics and the affordance of contemporary environments [14]. A third reason for interest is the necessity to study strategies that learners use in educational environments that rely on peer interaction. A social-constructivist view of learning often guides instructional design of online learning environments in which peer interaction is foundational. Past research in the field of SRL and metacognition has by large been focused on the individual learner. Future research necessitates taking into account the paradigm shift and explore regulation of learning in digital learning environments designed around peer-interaction.

\section{THEORY}

Research in the field of SRL has taken a turn. Reciprocal regulation between peers and groups of learners regulating their learning collectively, referred to as socially shared regulation, are now in the spotlight of several researchers [4][11], [15], [16]. Based on the theoretical model developed by Kaplan [17] (see Figure 1), a self-report tool to measure the perceived frequency of use of self-regulation strategies, including two co-regulation strategies, was used in this research. 
Table I

Phases and Learning Regulation Strategies Measured with ERICA [2]

\begin{tabular}{lll}
\hline Phase & Code & Regulation Strategy \\
\hline Anticipation & IAR & $\begin{array}{l}\text { Individual Anticipation of Materials and } \\
\text { References }\end{array}$ \\
Monitoring & IEC & $\begin{array}{l}\text { Individual Environmental Control } \\
\text { Assessment }\end{array}$ \\
& ITM & Individual Tracking and Monitoring \\
Decisions & IEM & $\begin{array}{l}\text { Collective Evaluation of Content } \\
\text { Individual Evaluation of Method }\end{array}$ \\
& CDM & Collective Decisions for Method change \\
\hline
\end{tabular}

A word about what is referred to in this paper when using terms to describe regulation of learning will be useful. In this paper designations concur with Kaplan's [18] in which co-regulation is used as an encompassing term to designate regulation of learning that involves interaction with others. Two categories are included under the banner of CoRegulation: Reciprocal Regulation and Collective Regulation. The former designates regulation from the standpoint of the individual in relationship with other persons, whereas the latter designates regulation taking place at the group level. Referring to collective regulation entails a change in the unit of observation - from the individual to the group as entity.

The individual and collective regulation of learning scale ERICA [2] enables to measure strategies at the macro-level [19]. Four macro-level regulation of learning strategies measured by ERICA are viewed as individual and two are viewed as collective. Strategies are summed up in Table I.

Measures at the macro-level enable to detect patterns in regulation. Patterns of regulation should be understood as snapshots within contextualized situations of learning that depict the group being studied within that situation at a specific moment in time. This approach provides for comparisons to better understand the interplay between environmental conditions and Self-and Co-Regulated Learning (SCRL). The aim of the research presented here was to compare results from two groupes of students with results from a previous study. In both studies the students took the same course in the same online first-year postgraduate program in Educational Sciences. As mentioned, in the present study two groups participated. Each group used much of the same resources but each had a different instructor. The studies explored strategies that contributed to the assessments learners made of their study methods. Individual Evaluation of the learning Method (IEM) was selected as the criterion for the studies to analyze the relationship between IEM and the other SCRL strategies measured with ERICA. IEM fits into the theoretical cyclic process of regulation at the step just prior to decision making. On the basis of IEM, a decision can be made to keep using a method already in use or to change methods during subsequent efforts (see Figure 1).

The previous study $(N=37)$ explored links between learn-

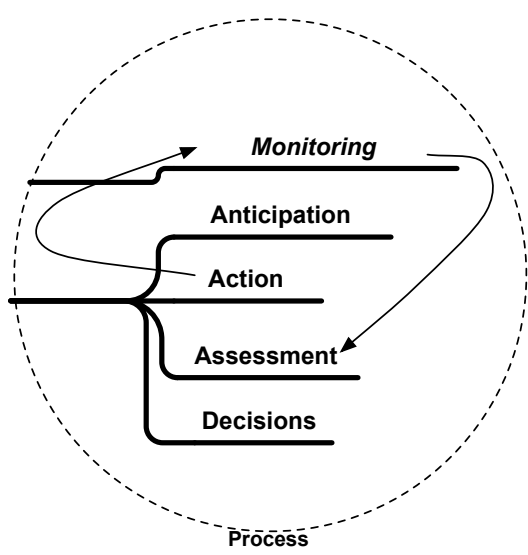

Figure 1. Regulation of Learning Phases Model [17]

ers' self-assessment strategies and other strategies to regulate learning, using multiple regression analyzes performed on data that was self-reported with ERICA by first-year postgraduate students during the 2016-17 academic year. The same terrain was used for the study presented here, with students taking the course during the 2017-18 academic year. In the 2016-17 study, the main strategy that contributed to IEM ( $71 \%$ of the proportion of variance explained by the model) was Collective Evaluation of Contents (CEC) targeted by the learning. CEC pertains to a collective strategy in which peers gauge and appraise the objects of knowledge at which they aim their learning. The model that emerged from that study had a second predictor variable. The second variable, which accounted for a smaller portion ( $29 \%$ of the proportion of variance explained by the model), was the control individuals exert on their learning environment, namely Individual Environmental Control (IEC). The model is represented in Figure II.

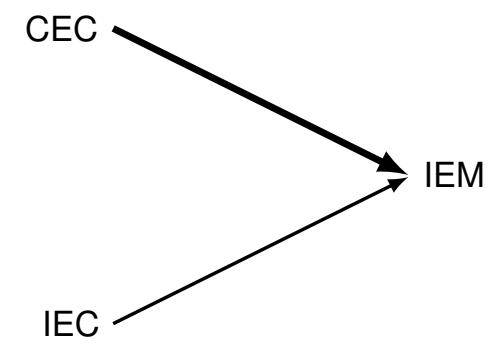

Figure 2. Model of Strategies of Regulation that Predict Self-Evaluation of the Learning Method Resulting from a Study with 2016-17 Master's Students (Adjusted $R^{2}=0.47$ ) [1]

\section{Method}

In this study, data was self-reported using an online version of the ERICA questionnaire [2], made available on a server using Drupal ${ }^{\mathrm{TM}}$ software and an installed Webform module. The questionnaire, which contains 30 items, was administered during the last week of a four week compulsory course on quantitative data analysis during the second semester of the 
2017-18 academic year. Participants were first-year students preparing for a Master's degree in Educational Sciences at a French university, enrolled in a distance education online program on the digital campus for education sciences. ${ }^{1}$ The Learning Management System (LMS) used was BlackBoard Learn $^{\mathrm{TM}}$. Students who had chosen to major in social work and healthcare education plus those majoring in adult education were assigned to group A. Students who had chosen to major in the formal education professions were assigned to group B. Each group had its own instructor.

The instructional design used with group A was based on the cooperative learning method Learning Together [20]. The instructional design deployed with group B used both individual and small group activities similarly to group A, but with more emphasis on individual activities. Participants were encouraged to respond to the questionnaire. The researchers' commitment to confidentiality and to the preservation of respondents' anonymity was communicated orally and on the questionnaire web-page.

Descriptive statistics pertaining to each group were computed. Next, a multivariate analysis of variance (MANOVA) was carried out to test the null hypothesis of differences between the two groups. Followed were multiple regression analyzes on the collected data to derive a self-evaluation of the learning method model or models. Models were then compared between those resulting from the present study and the model derived from the previous study [1].

\section{RESUlts}

Analyzes were performed using $\mathrm{R}$, version 3.4.3 [21]. Internal consistency analyzes of the measures carried out with ERICA were done using Chronbach's alpha to estimate reliability. Results were satisfactory for all dimensions: IAR $(\alpha=.77)$, IEC $(\alpha=.84)$, ITM $(\alpha=.81)$, CEC $(\alpha=.78)$, IEM $(\alpha=.73)$, CDM $(\alpha=.86)$.

Respondents $(N=70)$ were students from group A majoring in social work and health education plus those majoring in adult education ( $n=37 ; 81 \%$ female, $19 \%$ male; age $M=35.41, S D=7.13$ ) and students from group B majoring in the formal education professions ( $n=33 ; 85 \%$ female, $15 \%$ male; age $M=32.15, S D=5.35)$. Table II provides descriptive statistics for each regulation strategy per group. A $t$-test on age means indicated a small but statistically significant difference between the two groups $[t(68)=2.14, p=.036]$.

The next step consisted of comparing the two groups for differences in perceived frequency of use of strategies. A MANOVA was carried out on the regulation strategies variables. Results did not reveal significant differences in perceived use of regulation of learning strategies between the two groups $[F(1,55)=1.22 ; n s]$. As no significant differences were found, following analyzes were done on all respondents' data (groups A and B) as a whole.

\footnotetext{
${ }^{1}$ Formation et Ressources en Sciences de l'Éducation (FORSE) $<$ http://www.sciencedu.org $>$ is a digital campus run conjointly by two French universities and the French national centre for distance education.
}

Table II

Descriptive Statistics of Measured Regulation Strategies

\begin{tabular}{llllllllll}
\hline & \multicolumn{4}{c}{ Group A } & & \multicolumn{5}{c}{ Group B } \\
\cline { 2 - 4 } \cline { 8 - 10 } Strategy & Min & Max & $M$ & $S D$ & & Min & Max & $M$ & $S D$ \\
\hline IAR & 1.8 & 4.0 & 2.85 & 0.59 & & 1.2 & 4.0 & 2.91 & 0.71 \\
IEC & 1.0 & 4.0 & 2.92 & 0.79 & & 1.2 & 4.0 & 2.96 & 0.71 \\
ITM & 0.0 & 4.0 & 1.50 & 1.10 & & 0.0 & 4.0 & 1.73 & 1.05 \\
CEC & 1.0 & 3.4 & 2.28 & 0.65 & & 0.6 & 3.0 & 1.95 & 0.76 \\
IEM & 1.2 & 3.2 & 2.26 & 0.52 & & 1.0 & 3.0 & 2.10 & 0.60 \\
CDM & 0.0 & 3.0 & 1.34 & 0.80 & & 0.0 & 2.8 & 1.01 & 0.82 \\
\hline Note: Values for measured regulation strategies span from 0 to 4.
\end{tabular}

Analyzes that followed were intended to explore regulatory strategies (the independent variables) that are conducive to the self-evaluation of the learning method (the dependent variable). Multiple regression analyzes were performed for that purpose. A step-by-step (bidirectional) analysis, adequate for an exploratory phase [22], was performed using the Akaike Information Criteria (AIC). The resulting explanatory model indicated that the co-regulatory strategy Collective Evaluation of Content (CEC) as well as the individual regulatory strategy Individual Environmental Control (IEC), jointly contributed to the Individual Evaluation of Method (IEM) regulation strategy (see Table III). IEM pertains to the self-evaluation of the method the learner used for her or his learning. The result of the assessment of the linear model assumptions [23] warrants the model with the two predictor variables CEC and IEC (see Table IV).

Table III

Multiple Regression ANalysis of Regulatory StRategies EXPLANATORY OF SELF-EVALUATION OF LEARNING METHOdS

\begin{tabular}{|c|c|c|c|c|c|c|}
\hline & \multicolumn{6}{|c|}{ IEM } \\
\hline & $n$ & $\beta$ & $\beta$ error & $R^{2}$ & Adj. $R^{2}$ & $F$ \\
\hline IEC & & $0.18^{*}$ & 0.09 & & & \\
\hline CEC & & $0.21^{*}$ & 0.09 & & & \\
\hline & 63 & & & 0.17 & 0.14 & $(2,60)=6.03^{* * *}$ \\
\hline
\end{tabular}

Table IV

Assessment of THE Assumed Linear Model Assumptions

\begin{tabular}{llll}
\hline & Value & $p$ & Decision \\
\hline Global Stat & 1.29 & 0.86 & Assumptions acceptable. \\
Skewness & 0.17 & 0.68 & Assumptions acceptable. \\
Kurtosis & 0.91 & 0.34 & Assumptions acceptable. \\
Link Function & 0.21 & 0.65 & Assumptions acceptable. \\
Heteroscedasticity & 0.00 & 0.99 & Assumptions acceptable. \\
\hline
\end{tabular}

These results were similar to the ones found in the previous study though the proportion of variance explained was $14 \%$, a lower percentage to the one found in the previous study in which the proportion of variance explained was $47 \%$.

A final step consisted of calculating the relative importance of each contributing strategy to IEM. Following recommendations by Gromping [24], decomposing the variance using 
the LMG method was used. Metrics were normalized to sum to $100 \%$. The percentage of contribution to the variance by each predictor resulted in $55 \%$ for CEC and $45 \%$ for IEC, compared to $71 \%$ and $29 \%$ respectively in the previous study.

Illustrating the model ( $c f$. Figure II) will be helpful before proceeding to discuss results. An example of a strategy that belongs to the macro-level collective strategy of evaluation of the targeted learning content (CEC) is when learners have discussions with one another to calibrate targeted outcome. These discussions, combined (though to a lesser extent) with strategies pertaining to control over the learning environment (IEC), such as setting oneself up in a place where one will not be distracted when learning, predict learners' use of strategies for the evaluation of their individual learning methods (IEM). An example of a strategy that belongs to the latter is to sometimes question one's learning method. In other words, more discussions held among learners on terms of reference, plus increased attention to suitable conditions to learn in, are indicative of the more frequent practice of checking out adequacy of the way one is developing one's knowledge and reflecting on the cognitive processes (metacognition) used to comprehend information and improve mastery of the topic being learned.

\section{DiscusSiON}

Contrary to the previous study where the main strategy that contributed to self-evaluation of the learning method was $\mathrm{CEC}$, in the present study both CEC and IEC have a similar relative importance in their share of the proportion of the variance explained by the model. Additionally, although the same model emerged from both studies, there is a considerable difference between the proportion of variance explained by the model in the present study (14\%) and the previous one $(47 \%)$. Regardless, it is the same model that turned up in both studies.

One of the instructors (group A) was the same as the one in the previous study. He had used the same instructional design both times. The research reported here had participants studying with another instructor too (group B). Nevertheless, no statistically significant differences were found between the frequency of perceived use of regulation strategies by the students in each group. Perhaps the use of the same LMS, interfaces, basic learning material and a similar learning design contributed more strongly to perceived regulation of learning and so no significant differences were found. Future studies within different environmental conditions should help clarify this.

In both the present study and the previous one, CEC which is a collective strategy entailing discussion among learners, was linked to the individual strategy IEM. The latter concerns assessment of the learning process, as opposed to the former which is an assessment related to the targeted outcome. The analysis of data from these studies underlines the contribution of the co-regulatory strategy CEC to judgments the learners made as to the adequacy of their past individual learning processes in order to make fitting methodological choices. The assessment phase is crucial to the regulation of learning. As mentioned, variations between the two groups in the present study were not statistically significant. However, a difference in the proportion of the variance explained by the model in the present study compared to the previous one is apparent. Differences may be due to small changes in the characteristics of the learning environment (pedagogical method, instructor and group composition, etc.). Nonetheless, the need for control over the learning environment and the need for channels to communicate among peers in order to reciprocally gauge content related goals in view of adjusting learning methods, have implications for the designs of e-learning environments. The results of this research suggest implementing features in the software used for education as well as designing the digital environment on top of it in two ways. The first is by making it possible for learners to adjust the environment to suit their individual preferences. The second is by providing communication channels for learners to interact through.

The environment can be thought of in terms of choices about where one wishes to study (at one's desk at home, a public library, outdoors...), the sound in the environment (silence, music, chattering, chirping birds...), the lighting of the environment, its warmth and other comfort related aspects. These environmental considerations are independent of the use of materials and means of communication to support the learning. The environment can also be conceived of in terms of media and tools that in digital learning environments can be altered to varying degrees. Interactions between the learner and the digital environment can shape the environment. Depending on the design infrastructure, some adjustments could be yielded to learners. Adjustments could be the ability to shape an interface such as placing components of the interface at different locations on the screen. Adjustments could also be the ability for the learner to add components with specific services such as announcements from social network posts or to remove services such as an unused online calendar. Regarding communication services, digital environments often integrate forum modules for asynchronous discussions as well as chat modules for synchronous discussions. A messaging module is often integrated too. Other communication channels could be made available. Even if they are not, gateways to other media and applications can be opened as well as instructions can be given as to the option of using audio or video for online discussions using other tools. Most importantly is the need to implement e-learning environments in a manner that enables learners to have discussions among themselves.

\section{CONCLUSION}

The study put to test a model for self-evaluation of the learning method that resulted from a previous study [1] in similar environmental conditions. The model that followed from this research corroborates the one that turned up previously. This suggests that in likewise environmental conditions, analogous patterns of regulation of learning are present with regard to the evaluation by learners of their learning methods. Learners also perceived their frequency of use of strategies to regulate their learning in a comparable manner even though 
separate instructors were assigned to the groups in the present study. Beyond this first indication, strategies that contributed to individually evaluating methods used for learning were those strategies pertaining to control by learners over their learning environments as well as strategies pertaining to co-evaluation of the targeted learning contents. Both these macro-level strategies contributed to individuals' evaluation of their learning methods. However, the proportion of variance explained by the model was considerably lower in the new study. It was lower to such an extent that the model has little usefulness. Other still unidentified variables play important roles in the assessment of the adequacy of the deployed learning methods by online students.

Future studies using other research methods in parallel such as through the use of trace data on e-learning LMSs, should enable to observe the degree of association between self-reports and actual use of available control that digital environments offer as well as actual use of communication services by learners. Attempting to understand links between self- and co-regulation perceived use and actual usage will also enable further testing of the empirical validity of the selfevaluation of the learning method model.

\section{REFERENCES}

[1] J. Kaplan, "Coévaluation entre pairs apprenants comme échafaudage de la régulation du processus de l'apprentissage," ser. Symposium: Apprentissage autorégulé et régulation des apprentissages: le rôle de l'évaluation. CNAM, Paris: Les rencontres internationales du Réseau de recherche en éducation et en formation (REF 2017), July, 42017.

[2] J. Kaplan, M. de Montalembert, P. Laurent, and F. Fenouillet, "ERICA An instrument to measure individual and collective regulation of learning [ERICA - Un outil pour mesurer la régulation individuelle et collective de l'apprentissage],' European Review of Applied Psychology - Revue Européenne de Psychologie Appliquée, vol. 67, no. 2, pp. 79-89, 2017.

[3] B. J. Zimmerman and M. Martinez Pons, "Development of a structured interview for assessing student use of self-regulated learning strategies," American Educational Reasearch Journal, vol. 23, no. 4, pp. 614-628, 1986.

[4] S. Lajoie, "Metacognition, self regulation, and self-regulated learning: A rose by any other name?" Educational Psychology Review, vol. 20, no. 4, pp. 469-475, 2008.

[5] S. Järvelä, J. Malmberg, and M. Koivuniemi, "Recognizing socially shared regulation by using the temporal sequences of online chat and logs in CSCL," Learning and Instruction, vol. 42, pp. 1-11, 2016.

[6] N. Saab, "Team regulation, regulation of social activities or coregulation: Different labels for effective regulation of learning in CSCL," Metacognition Learning, vol. 7, no. 1, pp. 1-6, 2012.
[7] S. Volet, M. Vauras, and P. Salonen, "Self- and social regulation in learning contexts: An integrative perspective." Educational Psychologist, vol. 44, no. 4, pp. 215-226, 2009.

[8] A. Efklides, "Metacognition: Defining its facets and levels of functioning in relation to self-regulation and co-regulation." European Psychologist, vol. 13 , no. 4, pp. 277-287, 2008.

[9] P. Salonen, M. Vauras, and A. Efklides, "Social interaction - what can it tell us about metacognition and coregulation in learning?" European Psychologist, vol. 10, no. 3, p. 199, 2005.

[10] J. Kaplan, "Learning strategies and interpersonal relationships of students learning cooperatively online," in Learning Technology for Education in Cloud - The Changing Face of Education, L. Uden, D. Liberona, and B. Feldmann, Eds. Springer, 2016, pp. 103-111.

[11] _ "Co-regulation in technology enhanced learning environments," in Learning Technology for Education in Cloud. MOOC and Big Data, L. Uden, J. Sinclair, Y.-H. Tao, and D. Liberona, Eds. Springer International Publishing, 2014, pp. 72-81.

[12] A. Bandura, "Social cognitive theory of personality," in Handbook of Personality - Theory and Research, L. A. Pervin and O. P. John, Eds. New York: Guilford Press, 1999, pp. xiii, 738.

[13] _ Social Learning Theory. New York, NY: General Learning Press, 1971.

[14] M. Hammond, "What is an affordance and can it help us understand the use of ICT in education?" Education and Information Technologies, vol. 15, no. 3, pp. 205-217, Sep 2010.

[15] S. Volet, M. Summers, and J. Thurman, "High-level co-regulation in collaborative learning: How does it emerge and how is it sustained?" Learning and Instruction, vol. 19, no. 2, pp. 128-143, 2009.

[16] J. Kaplan, L'autodirection dans les apprentissages coopératifs: Le cas des Cercles d'Étude. Sarrebruck: Éditions Universitaires Européennes, 2010.

[17] —, "L'autodirection dans les apprentissages coopératifs - le cas des cercles d'étude [self-direction in cooperative learning - the case of study circles]," Ph.D. dissertation, Paris 10 University, Nanterre, 2009.

[18] — , "Les stratégies d'autorégulation collective des apprenants adultes en e-formation," in e-Formation des adultes, A. Jezegou, Ed. Louvainla-Neuve: De Boeck Supérieur, In Press.

[19] J. A. Greene and R. Azevedo, "A macro-level analysis of SRL processes and their relations to the acquisition of a sophisticated mental model of a complex system," Contemporary Educational Psychology, vol. 34, no. 1, pp. 18-29, 2009.

[20] D. W. Johnson, R. T. Johnson, and K. A. Smith, "Cooperative learning: Increasing college faculty instructional productivity," ASHE-ERIC Higher Education Reports, vol. 20, no. 4, p. 157, 1991.

[21] R Core Team, R: A Language and Environment for Statistical Computing, R Foundation for Statistical Computing, Vienna, Austria, 2017. [Online]. Available: https://www.R-project.org/

[22] S. W. Menard, Applied logistic regression analysis. Thousand Oaks, Calif.: Sage Publications, 1995.

[23] E. A. Peña and E. H. Slate, "Global validation of linear model assumptions," Journal of the American Statistical Association, vol. 101, no. 473, pp. 341-354, 2006, pMID: 20157621.

[24] U. Grömping, "Variable importance in regression models," Wiley Interdisciplinary Reviews: Computational Statistics, vol. 7, no. 2, pp. 137$152,2015$. 